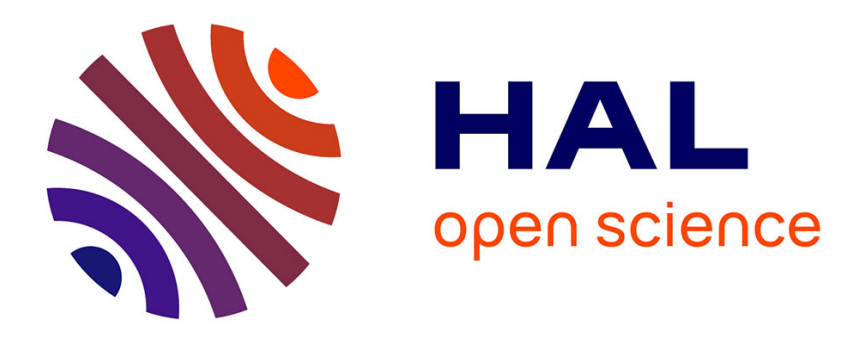

\title{
Small angle neutron scattering on periodically deformed polymers
}

\author{
A.R. Rennie, R.C. Oberthür
}

\section{To cite this version:}

A.R. Rennie, R.C. Oberthür. Small angle neutron scattering on periodically deformed polymers. Revue de Physique Appliquée, 1984, 19 (9), pp.765-768. 10.1051/rphysap:01984001909076500 . jpa00245255

\section{HAL Id: jpa-00245255 https://hal.science/jpa-00245255}

Submitted on 1 Jan 1984

HAL is a multi-disciplinary open access archive for the deposit and dissemination of scientific research documents, whether they are published or not. The documents may come from teaching and research institutions in France or abroad, or from public or private research centers.
L'archive ouverte pluridisciplinaire HAL, est destinée au dépôt et à la diffusion de documents scientifiques de niveau recherche, publiés ou non, émanant des établissements d'enseignement et de recherche français ou étrangers, des laboratoires publics ou privés. 


\title{
Small angle neutron scattering on periodically deformed polymers
}

\author{
A. R. Rennie \\ Institut für Phys. Chemie, Universität Mainz, 6500 Mainz, F.R.G. \\ and R. C. Oberthür \\ Institut Laue-Langevin, 156X, 38042 Grenoble Cedex, France
}

\begin{abstract}
Résumé. - La diffusion des neutrons aux petits angles par des échantillons périodiquement déformés est une extension des méthodes actuellement disponibles pour l'étude de la dynamique moléculaire des polymères. Dans cet article nous décrivons un appareil pour produire de larges déformations cycliques, jusqu'à des fréquences de $10 \mathrm{~Hz}$, ainsi que la méthode d'acquisition des données conduisant aux spectres correspondant aux différentes étapes de la déformation. Quelques résultats de l'étude d'un réseau de polydiméthyle siloxane soulignent l'intérêt de cette technique.
\end{abstract}

\begin{abstract}
Small angle neutron scattering from periodically deformed samples is a useful extension of the methods presently available for the study of molecular dynamics of polymers. In this paper we describe apparatus that has been used to produce large cyclic deformations at frequencies upto $10 \mathrm{~Hz}$ and the principles by which data is collected to give spectra corresponding to different states of strain of the sample. Some data on model polydimethylsiloxane networks is given as an illustration of the value of this technique.
\end{abstract}

\section{Introduction.}

Neutron scattering has proved a useful tool for the investigation of a wide range of structures such as those of single molecules in polymers and domains in magnetic materials $[1,2]$. Dynamic experiments can also be performed in which the momentum transferred to the scattered neutron is measured to determine the time or frequency dependent structure factor. A lower limit on the frequency of processes that can be studied by quasi-elastic scattering experiments about $5 \times 10^{8} \mathrm{~Hz}$ - is given by the accuracy with which these measurements can be made [3]. Elastic scattering from non-equilibrium structures can provide information on a molecular scale about dynamic processes. Even using a high flux reactor as the neutron source and two dimensional position sensitive detectors, the normal measurement time for a small angle neutron scattering spectrum is several minutes. Observation on rapidly quenched specimens [4] goes only a little way to reducing the gap between conventional elastic scattering experiments and spin-echo neutron scattering.

A technique that can further extend the range of dynamic experiments is to scatter from a sample that is undergoing cyclic structural change. Each cycle is divided into time intervals separately recorded and averaged over many periods. In this way sufficient data can be accumulated for good elastic spectra of molecular processes that occur at relatively high frequencies. This method has been applied previously to wide angle X-ray studies [5] as well as light scattering [6] and infra-red spectroscopy [7]. We will describe in this paper how the method has been applied to mechanically deformed polymers with a neutron small angle spectrometer. The following sections will first discuss the essential physical principles before describing the apparatus and concluding with a brief summary of some results and the potential of the method.

\section{Principles.}

The limit in time resolution that can be achieved in elastic scattering is governed by the velocity spread, $\Delta v$, of the neutron beam. In the time of flight between the sample and the detector, neutrons scattered in an infinitesimal interval will spread over a time, $\Delta t$, given by

$$
\Delta t=\frac{d}{v} \cdot \frac{\Delta v}{v}
$$


where $d$ is the distance from the sample to the detector. As the fractional spread in wavelength, $\left(\frac{\Delta \lambda}{\lambda}\right)$, is equal to the fractional spread in velocity, equation (1) can be rewritten as

$$
\Delta t=\frac{d}{v} \cdot\left(\frac{\Delta v}{v}\right)=\frac{d}{v} \cdot\left(\frac{\Delta \lambda}{\lambda}\right)=\frac{\mathrm{d} m \lambda}{h} \cdot\left(\frac{\Delta \lambda}{\lambda}\right)
$$

where $h$ is Planck's constant and $m$ is the mass of the neutron. The full consequences of this equation for the limits to this type of experiment are discussed elsewhere [8]. Here we make only two comments, first the time resolution for a given momentum transfer is determined by the wavelength spread of the incident beam. If the spatial resolution of the detector is limited, altering the detector distance, $d$, with the wavelength, $\lambda$, cannot decrease $\Delta t$. Secondly the magnitude of $\Delta t$ is dependent on $\Delta \lambda / \lambda$; typically for a mechanical velocity selector this is about $10 \%$ but for a crystal monochromator can be better than $1 \%$. Including the fundamental constants in equation (2) we obtain the following relation :

$$
\Delta t / \mathrm{ms}=2.5\left(\frac{\Delta \hat{i}}{\lambda}\right)\left(\frac{i}{\mathrm{~nm}}\right)\left(\frac{d}{\mathrm{~m}}\right) .
$$

For a small angle scattering experiment we might have $d=5 \mathrm{~m}, \lambda=0.8 \mathrm{~nm}$ and $(\Delta \lambda / \lambda)=10 \%$ for which we find $\Delta t=1 \mathrm{~ms}$. This limit is obviously much lower for wide angle scattering experiments with faster neutrons and a crystal monochromator.

As the time limit $\Delta t$ is much shorter than that required to measure a diffraction pattern we have decided to study periodic deformation of our sample. Although the response is not always so straightforward as that due to a single, rapid strain, it allows us better to exploit the potential of neutron scattering in the study of molecular dynamics of polymers. We are restricted to the study of invariant cyclical processes but there is compensation in the simplicity of data collection.

Each cycle is divided into intervals and a control signal given at the start of each interval. The neutron counts from the detector are stored in one set of memory locations until a control signal is received when the next set of locations are used. After a predetermined number of signals, the data is once more added to the first set. Provided that an unambiguous start signal is available, it is very easy to relate data to different points in the strain cycle.

\section{Apparatus.}

For these experiments we have used the small angle spectrometer D11 at the ILL, Grenoble [9]. It was necessary to deform samples cyclically at frequencies upto $10 \mathrm{~Hz}$ and provide the synchronised control pulses. A few modifications to the control program and electronics were also needed. In order to keep the equipment simple, a mechanical system operating entirely in air was chosen to generate linear reciprocating motion from a continuously turning motor shaft.

A schematic diagram of the apparatus is shown in figure 1. Two cross-heads are driven symmetrically above and below the neutron beam in order that

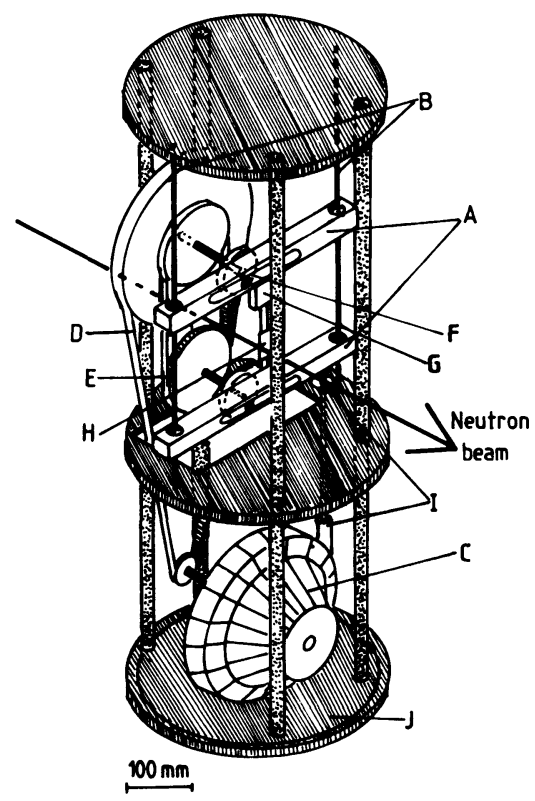

Fig. 1. - Schematic diagram of the stretching apparatus. $A$ are cross-heads fitted with ball bushes that slide on the guide rods $B$. C is a d.c. motor with a belt drive ( $D$ and $E$ ) to two discs with eccentrically mounted pivots, F. These are shown in more detail in figure $2 . \mathrm{G}$ is a load cell to measure the force on the sample, $\mathrm{H}$. I is a position transducer. The angle decoders are hidden from view on the upper and lower driven shafts.

measurements are always made on the same area of the sample. The cross-heads are fixed to ball bushes which move freely on ground steel guide rods. A diagram of the scotch yoke and eccentrically mounted roller bearing that provides the linear motion is given in figure 2 . The two discs with the pivots have numerous fixing positions so that a choice of deformations between $10 \mathrm{~mm}$ and $150 \mathrm{~mm}$ is readily available; they are driven in anti-phase by a fibre reinforced belt. The upper shaft has a similar belt drive with a $4.8: 1$ speed reduction from the shaft of a d.c. motor.

The high torque motor (Brown-Boveri Type MC23) has a thyristor regulated power supply which uses as negative feedback the voltage from a tachogenerator on the motor shaft. Forces on the sample upto $300 \mathrm{~N}$ are possible. Frequencies between $0.05 \mathrm{~Hz}$ and $10 \mathrm{~Hz}$ are stable to better than $1 \%$. A force transducer between the sample clamp and the upper cross-head allows the stress to be monitored; a position transducer between the base plate and the lower crosshead provides an analogue strain signal (this is always sinusoidal with time). Due to the large forces 


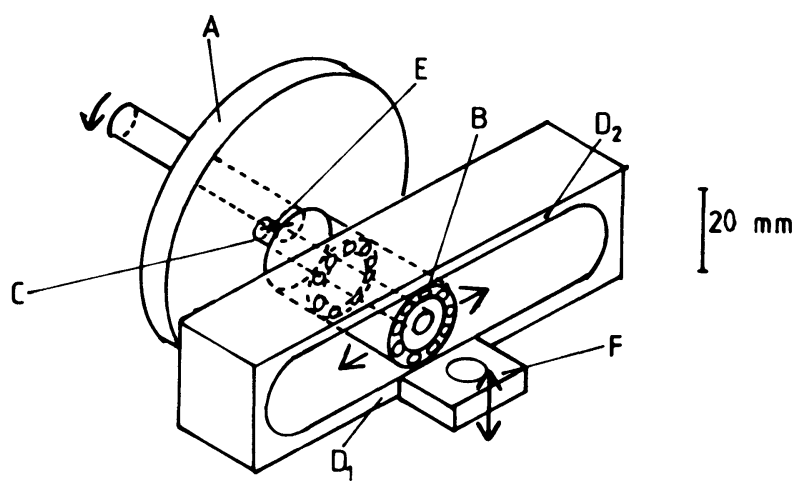

Fig. 2. - Details of the eccentric pivot and scotch yoke. $A$ is a continuously rotating disc on which $B$ an eccentrically mounted roller bearing is fixed at the point $C$. $D$ is the scotch yoke. The roller moves alternately on the surfaces $D_{1}$ and $\mathrm{D}_{2}$ which are machined to allow the minimum possible play. The line $\mathrm{E}$ shows the separation between the centre and the pivot point - in practice there are many possible fixing positions to allow a wide range of extensions. $F$ is the support for the sample clamp.

and accelerations a heavy steel frame and rigid support is needed. Figure 3 is a photograph of the equipment in the sample position of the spectrometer.

The pulses used to control data collection (and

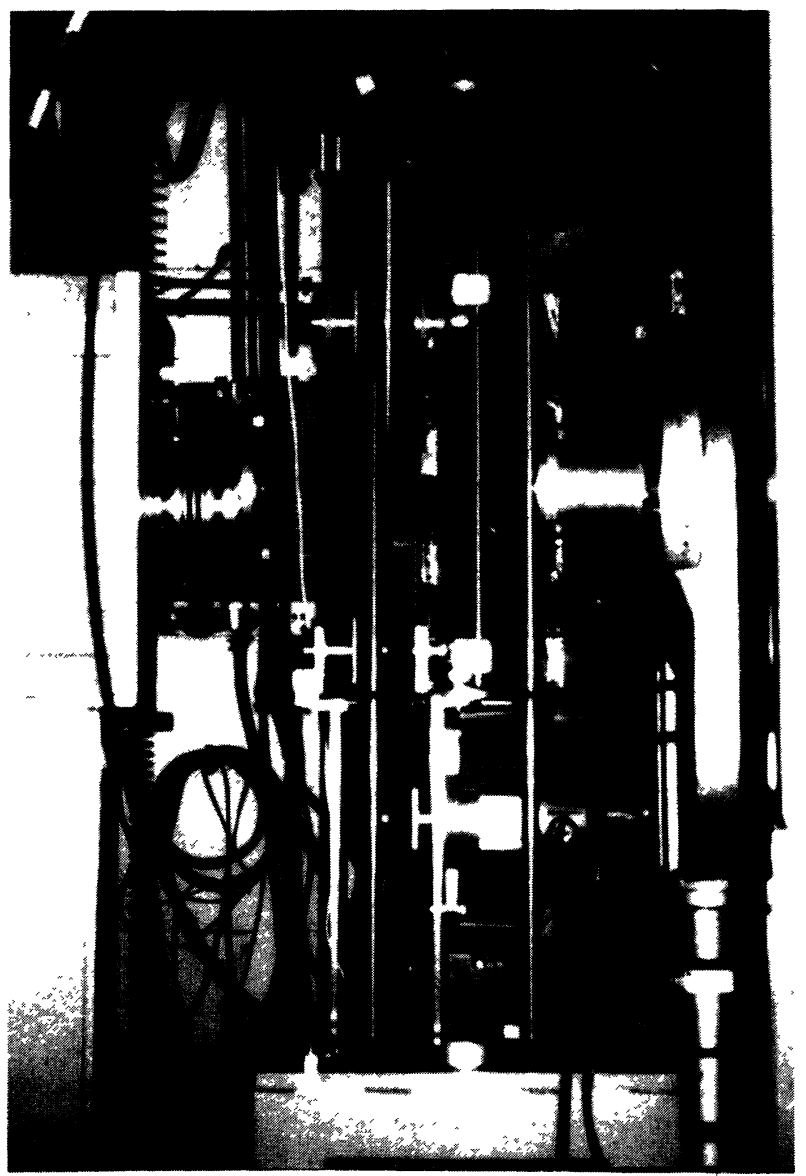

Fig. 3. - The cyclic stretching apparatus in the sample position of the D11 spectrometer of the ILL, Grenoble. measure frequency) are generated by angle decoders with photo-diodes. These switch a stabilized $+5 \mathrm{~V}$ supply to give a start signal which can be adjusted to a known point in the cycle, and 32 increment pulses per revolution. The control of the spectrometer was changed so that data collection can occur in 32 time channels. Detector counts on this spectrometer are stored in a memory external to the control computer on a CAMAC standard crate. This was extended to give sufficient space for 32 spectra (from the 64 by 64 element multidetector). The start address for storage of the spectra is provided by the CAMAC hardware and is incremented by the control pulses from the mechanical apparatus. In this way the spectra always correspond to a known state of strain of the sample without the need for elaborate control of the motor speed to maintain phase with the clock of the computer system. There is no need for a fast data collection program to run continuously which frees the computer to perform other tasks.

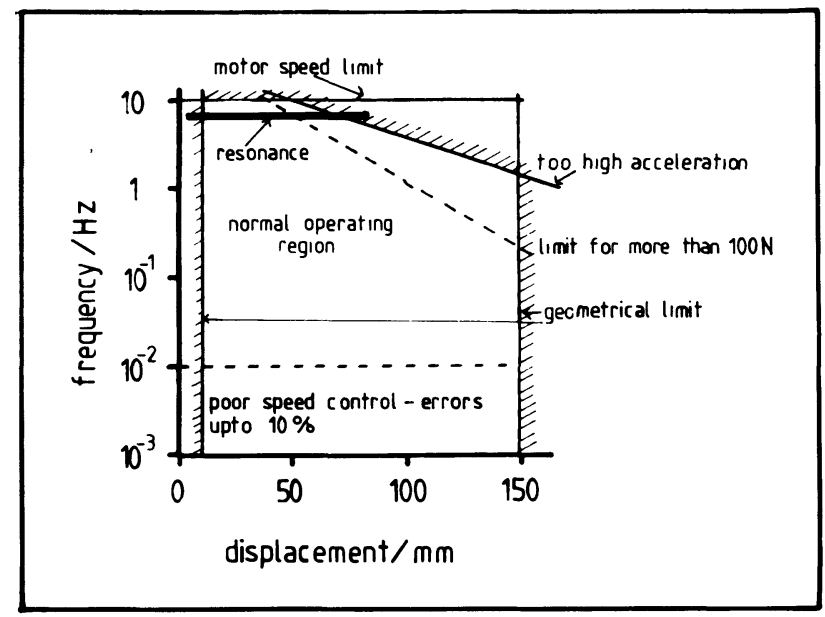

Fig. 4. - Limits of operation of the mechanical stretching apparatus.

The limits of performance of the equipment are shown in figure 4 . Because of a resonance the frequency region around $7 \mathrm{~Hz}$ is not usable : the entire apparatus swings in a vertical plane parallel to the sample. The apparatus has been tested and successfully run for several days measurement at frequencies between 0.1 and $10 \mathrm{~Hz}$ and seems well suited to large extensions upto this speed.

\section{Results and conclusions.}

The apparatus was built with the study of elastomers in mind. Conformation of deuterated paths in a network can be observed by small angle neutron scattering. As an example of the potential of the technique figure 5 shows some results from a study of model polydimethylsiloxane elastomers carried out in collaboration with the CRM, Strasbourg [10]. The radius of gyration of a molecule is readily determined from the scattering pattern [2]. In this material 


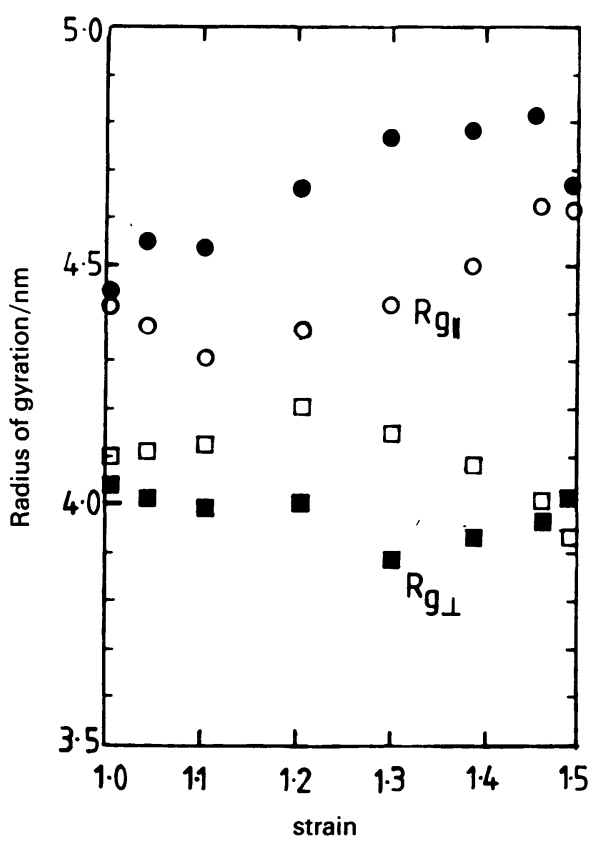

Fig. 5. - Radius of gyration plotted against tensile strain for a model polydimethylsiloxane network. This material is made by end linking chains $\left(M_{n}=10000\right)$ at tetrafunctional groups. The open symbols $(O, \square$ for directions parallel and perpendicular to the strain respectively) show the conformation as the network is stretched at a frequency of $10 \mathrm{~Hz}$. The corresponding filled symbols show the relaxation in the second half of the cycle. labelled paths are end linked and so we observe only the conformation between cross-link points. Clear hysteresis is shown both parallel and perpendicular to the strain for this sample strained at $10 \mathrm{~Hz}$. This is indicative of a molecular relaxation in this time regime that can not be directly observed by other means. This and other data will be discussed fully in a forthcoming paper [10].

The method is clearly valuable in extending the range of dynamic neutron scattering experiments, a broad range of processes are now available to direct study. Extensions to higher frequencies are clearly possible for both mechanical deformation and electromagnetic response. The present apparatus is already being adapted for use with a wide angle diffractometer and will be applied to the study of strain induced crystallization and deformation of filled rubbers amongst other potential experiments.

\section{Acknowledgments.}

We would like to thank our many colleagues (too numerous to mention individually) who have provided good advice and help in the construction of this apparatus and the implementation of this method of measurement. The work in Mainz was supported by the Bundesministerium für Forschung und Technologie. The neutron scattering experiments were performed at the ILL, Grenoble.

\section{References}

[1] Souires, G., Thermal Neutron Scattering (Cambridge U.P.) 1978.

[2] Maconnachie, A. and Richards, R. W., Polymer 19 (1978) 739-762.

[3] Heidemann, A., Howells, W. S. and Jenkin, G. Springer Lecture Notes on Physics 128 (1980) 122.

[4] Picot, C., Duplessix, R., Decker, D., Benoit, H., Bouḱ, F., Cotton, J. P., Daoud, M., Farnoux, B. JANNINK, G., NierliCh, M., DEVRIES, A. J. and Pincus, P., Macromolecules 10 (1977) 436-442.
[5] Kawai, H., Itoh, T., Keedy, D. A. and Stein, R. S., J. Polym. Sci. B 2 (1964) 1075-1078.

[6] Hashimoto, T., Ph. D., Thesis University of Massachusetts Amherst (1970).

[7] Burchell, D. J., Lasch, J. E., FarRis, R. J. and Hsu, S. L., Polymer 23 (1982) 965-968.

[8] Oberthür, R. C., Proceedings of this workshop.

[9] Ibel, K., J. Appl. Crystallogr. 9 (1976) 296-309.

[10] Herz, J., LapP, A., Oberthür, R. C., Picot, C. and RenNiE, A. R., to be published. 